\title{
Modification of the human development index in Ukraine in the regional aspect
}

\author{
Galyna Nazarova ${ }^{1}$, Volodymyr Volikov ${ }^{2}$ and Alina Demianenko ${ }^{3}$ \\ ${ }^{1}$ Simon Kuznets Kharkiv National University of Economics, Nauky ave. 9-a, 61166 Kharkiv, Ukraine \\ ${ }^{2}$ North-East Scientific Center of the NAS of Ukraine and MES of Ukraine, Bagalíy str. 8, 61002, \\ Kharkiv, Ukraine \\ ${ }^{3}$ Simon Kuznets Kharkiv National University of Economics, Nauky ave. 9-a, 61166 Kharkiv, Ukraine
}

\begin{abstract}
The paper presents the results of research on the modification of the traditional index of human development to assess its level in Ukraine in the regional aspect. The difference between the proposed modified human development index from existing approaches is the inclusion of an additional component of human development: the development of information and communication technologies, the updating of the indicator system by the component "education" and "environmental welfare" in accordance with the domestic conditions of the development of society, as well as the method of determining weighting coefficients to calculate the integral index. In the process of research, the following methods have been used: the method of generalization, comparison, system analysis and hierarchy analysis method. The calculation of the modified index of human development was carried out on the example of statistical data of regions of Ukraine; the period of research was selected 2015-2017. The results of the measurement demonstrate the presence of the marked unevenness of Ukrainian regions by the level of human development.
\end{abstract}

\section{Introduction}

The study of key tendencies in human development is an important element of assessing the level of socio-economic development. Careful analysis, statistical data processing, comparison and confrontation will make it possible to draw appropriate conclusions regarding the decision to choose the future direction of human development, to work out or adjust the national development strategies of a country or region.

It should be noted that with the transition of humanity to a new stage of development and a shift in emphasis on the need to ensure the well-being of people and society, it is information and communication technologies (hereinafter - ICT) offer great opportunities for socio-economic development. As L. Kochubei notes, "information technologies very quickly became a vital stimulus for the development of not only the world economy, but also other spheres of human activity" [1]. Modern society is flooded with huge information flows, and the development of ICT penetrating practically all spheres of human activity became the driving force for change and accelerated development of society [2].

Giving statistical confirmation of this thought, as of December 31, 2017, more than $54.4 \%$ of the world's population has access to the Internet and this number increases every day [3]. Among the $20 \%$ of the poorest households only 7 out of 10 have a mobile 
telephone. Bringing an interesting statistical comparison by T. Pospelova, we agree that "the number of poorer households with a mobile phone is bigger than those who have access to the toilet and clean drinking water" [4]. So, it is expected that the dynamic development of ICT will increase the opportunities for human development, prosperity and social integration.

Information and knowledge today become the most important resource of humanity [59], determining not only the progress of the economy and culture in high-tech areas of activity, but also determine the speed and nature of the transformation of human development and influence on it from various institutions [9]. Therefore, the inclusion of this trend in the human development assessment system is considered to be well-founded both at the theoretical and practical levels.

\section{Problem Statement}

Among the most popular methods for evaluating complex, difficult formalized processes in world practice is using a single indicator - an integral indicator. So, for the purpose of determining the level of human development, UNDP specialists for the first time developed a methodology for measuring it, proposing the use of the integral index of human development [10]. The proposed methodological approach laid the foundation for further research in the direction of improving the methods for evaluating the process of expanding human potential.

The results of the authors' thorough study of peculiarities to the evaluation of human development in Ukraine and abroad [11-17], allowed to identify shortcomings. Thus, in determining the level of human development, the main shortcomings in our opinion are: the complication of a large number of indicators, not taking into account the quality of education components of the "education", not taking into account all levels of education: pre-school, full secondary and higher education, not taking into account the component of ICT, the same weight coefficients for components of human development generate the need for improvement the approach to human development assessment that takes into account the peculiarities of modern domestic human development conditions and focuses on the "innovation". The results of the authors' thorough study of peculiarities of the human development process, in addition to being simple, accessible and easy to apply.

\section{Research Questions}

In the process of research the authors faced the following questions:

What components of human development are the most important in determining its level in conditions of innovative society development?

What indicators should be used to measure ICT in the regions of Ukraine?

What requirements of a system of indicators and calculation algorithm should be followed in order to avoid contradictions in the evaluation of human development?

How to determine the weight coefficients for each component of human development?

\section{Purpose of the Study}

Improving the approach to assessing the level of human development, taking into account the development of ICT and the features of the domestic conditions.

\section{Research Methods}


To improve the approach to assessing the level of human development, the authors used the following methods: the method of theoretical generalization - to determine the list of major problems in determining the real level of acquired human potential; comparison and system analysis - to select the most important indicators of the main components of human development; the expert survey method and the hierarchy analysis method are used to determine the weight coefficients of the components of human development.

Thus, in order to calculate the modified index of human development, we propose the use of weighted coefficients calculated using the analytical hierarchical process method. After all, this method is a more reliable and consistent method of assigning estimates to weight factors by experts and is based on a pairwise comparison of each aspect of human development to determine the relative importance.

Table 1. The results of the analytical hierarchical process for the determination of weighting factors in the assessment of the modified index of human development

\begin{tabular}{|l|c|c|}
\hline Components of human development & Values of weight coefficients & Measure of consistency \\
\hline 1. Longevity & 0.379 & 5.5146 \\
\hline 2.Education & 0.108 & 5.4440 \\
\hline 3. Economic welfare & 0.254 & 5.4186 \\
\hline 4. Environmental well-being & 0.173 & 5.3071 \\
\hline 5. ICT & 0.086 & 5.3304 \\
\hline \multicolumn{2}{|c|}{ Consistency Index } & 0.101 \\
\hline \multicolumn{2}{|c|}{ Random Consistency Index } & 1.12 \\
\hline \multicolumn{2}{|c|}{ Consistency Ratio of expert opinions } & 0.090 \\
\hline
\end{tabular}

As a result of calculations it is determined that Consistency Index is 0.101 . Consequently, Consistency Ratio is equal to $0.090(0.101 / 1.12)$. It should be noted that according to the results, the Consistency Ratio does not exceed the value of 0.10 according to the Saaty, it means that the experts were fairly objective in their assessments. Thus, the author proved the consistency of expert opinions, the calculated values are not random, which provides the basis for using the results of an expert survey in further research.

\section{Findings}

In the process of research it was clarified that the main three components of human development: longevity, education and economic welfare of the population and the indicators that determine their level, are in all methods considered by the authors. This suggests that these three components are the most important, and their use is justified and scientifically sound. Thus, the component of "longevity" is proposed to be evaluated according to the traditional indicator - the expected life expectancy at birth (formula 1). Where actual value is the actual value of the expected life expectancy at birth in the region, measured over the number of years. The standard formula used by the UNDP is used to rate the indicator [18].

$$
L=\frac{\text { actual value }-20}{85-20},
$$

Measurement of the education component requires improvement and complementarity. In order to determine the level of educational potential in the country, according to the traditional model of human development measurement, it is proposed to use expected years of schooling and mean years of schooling. While higher and pre-school education is not taken into account, also there is no assessment of the quality of education.

In our opinion, the use of the above indicators to measure the educational situation in the regions of Ukraine with a view to comparing them is not feasible. After all, firstly, the term of studying for obtaining a complete general secondary education in institutions of 
general secondary education is the same in all regions of Ukraine and is eleven years [19]; and secondly, there is no consideration of the effective indicator of the quality of education. So, we agree with the opinion of O. V. Makarova and O. M. Hladun [20] about the necessity of attracting indicators that could reflect all levels of education: pre-school education, full secondary education and higher education, and we consider it expedient to overcome this idea when forming the composition of indicators of this the component. Thus, the list of indicators selected to assess the education is given below (formula 2).

$$
E d=\frac{\sum_{i=1}^{3} E_{i}}{3}
$$

where: $E_{l}$ is the provision of children by pre-school educational institutions in a year in the region; $E_{2}$ is the level of coverage of the population by secondary and higher education per year in the region; $E_{3}$ is the quality of education (the proportion of people who have an average and high score on the results of the external independent evaluation to the total number of external independent evaluation participants per year in the region).

Economic welfare component is determined by the indicator - GRP per capita (formula 3 ), where "actual value" is the actual value of GDP per capita, and "min" and "max" are respectively the minimum and maximum value of GRP per capita in Ukraine.

$$
E W=\frac{\ln (\text { actual value })-\ln (\min )}{\ln (\max )-\ln (\min )}
$$

The above-mentioned components are insufficient to determine the level of human development, because the classical system for calculating the level of human development does not take into account the ecological component, which contradicts the definition of the category of human development proposed by UNDP in 2010. Thus, "the formation of just and sustainable development on our planet" [21] is extremely important, which creates the need to supplement the component "environmental well-being" and indicators that determine the state of the environment in the region:

$$
E N=\frac{\sum_{i=1}^{3} E c o_{i}}{3},
$$

where: $\mathrm{ECO}_{1}$ is the level of waste utilization (the share of waste utilized to the total amount of waste generated, per year); $\mathrm{ECO}_{2}$ - forest area (specific gravity of the area covered with forest vegetation of forest areas to the total area of forest areas, per year); $E \mathrm{Co}_{3}$ is the level of water supply (percentage of water resources per inhabitant, per year).

The consideration of ICT in measuring human development was studied by Ukrainian scientists: O. Vlasiuk, S. Pyrozhkov [22]. The researchers drew attention to the need to evaluate ICT in human development. The list of indicators for assessing of ICT is marked by indicators: the number of TVs, radios and landlines. But we draw attention to the obsolete some indicators and consider expedient in the assessment of human development to take into account a comprehensive index (formula 5). The comprehensive ICT index would include: the level of use of stationary communication $\left(I_{1}\right)$; level of mobile communication usage $\left(I_{2}\right)$; and the level of Internet usage $\left(I_{3}\right)$ that are calculated as follows:

$$
I C T=\frac{\sum_{i=1}^{3} I_{i}}{3},
$$

A generalized system of indices of the modified index of human development is presented in Fig. 1.

The next important issue in determining the objective level of human development is the determination of weight coefficients for each of the components. The results of expert evaluation using the hierarchy analysis method allow solving this issue. The obtained results and confirmed by calculation of Consistency Ratio of expert opinions allow to be used for the calculation of the modified index of human development (MHDI), the formula for measuring which is as follows (formula 6):

$$
M H D I=L \times 0.379+E d \times 0.108+E W \times 0.254+E N \times 0.173+I C T \times 0.086,
$$

where: $0.379,0.254,0.173,0.108,0.086$ are weight coefficients for each of the components of the modified index of human development. 


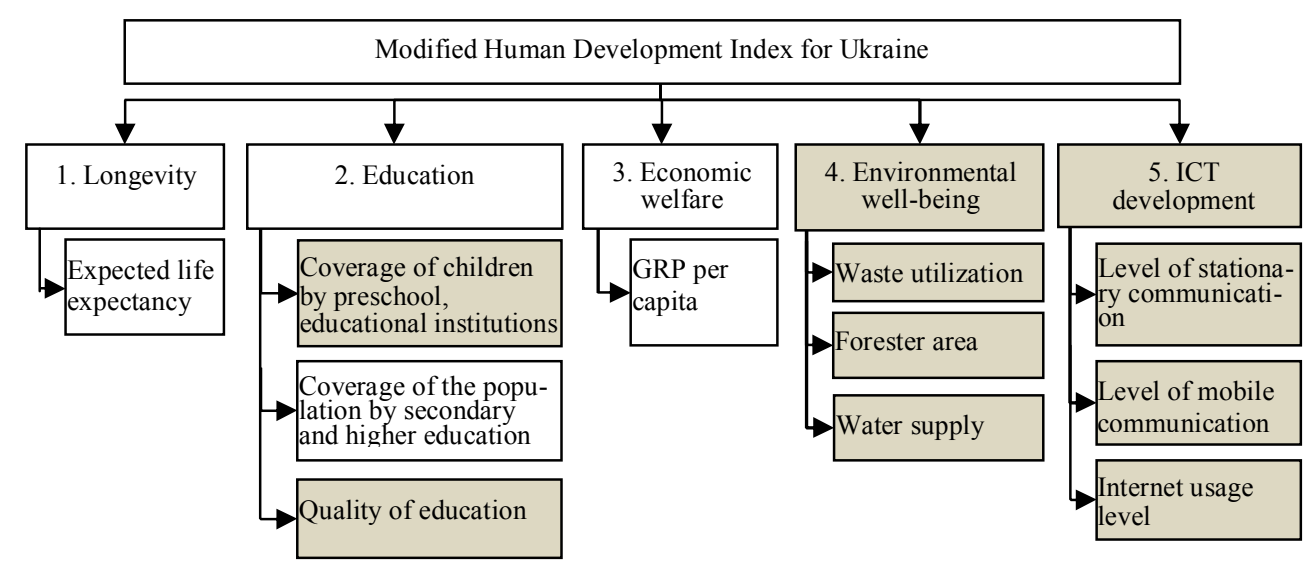

Fig. 1. Scheme of indices of the modified index of human development for Ukraine Note: shaded squares are the author's addition and clarification

The calculation of the modified index of human development was based on open access statistics [23] for 2015-2017 (Fig. 2).

As a result of the calculations revealed a pronounced unevenness in the level of human development of the regions of Ukraine. The determining factor is the low economic and environmental condition in the regions. The most favorable conditions for the development of human potential were recorded in Dnipro, Zaporizhzhia, Lviv, Odesa, Poltava, Cherkasy, Kharkiv and other regions. The lowest rates were recorded in Ternopil, Kirovograd, Mykolaiv, Kherson and others. Overall, there is a tendency to increase by 0.1 percentage points on average, indicating improvement in some regions. However, according to the human body's measurement of human slag, that proposed by UNDP, a high level of human development (which is defined in the range of 0.8 to 1 ) is absent. In Ukraine, the average and low level of development of human potential prevails. The obtained results will enable us to formulate the main recommendations for eliminating the sharply expressed unevenness of the development of the regions of Ukraine.

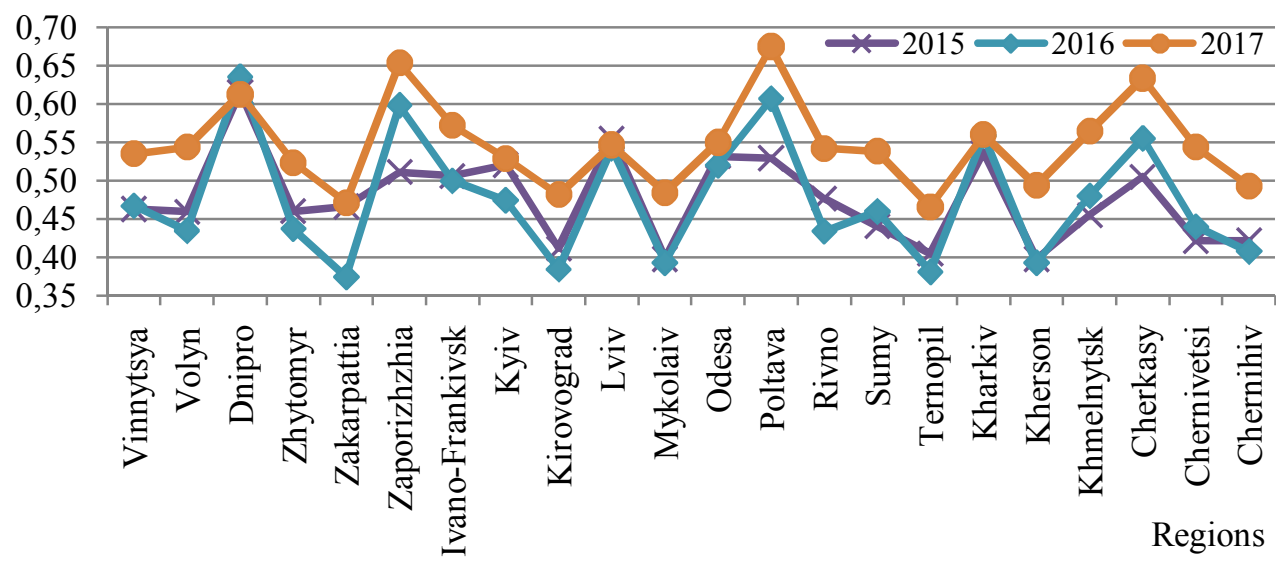

Fig. 2. Dynamics of change of the MHDI in the regional section in Ukraine Note: data exclude the temporarily occupied territory of the Autonomous Republic of Crimea and the part of temporarily occupied territories in Donetsk and Luhansk regions 
The transition of humanity to a new stage of development determines the need to ensure the well-being of people and constant expansion of opportunities and freedoms. It is hard not to notice that modern society is full of huge flows of information, and the development of ICT penetrating practically in all spheres of human activity have become the driving force for change and accelerated development of society. That is why the methodology for determining the level of human development must meet the modern requirements, which creates an objective need for modification the index of human development.

The difference between the proposed modified index of human development, in comparison with the existing, is the inclusion in the system of assessment of the additional component of human development - ICT, updating indicators of the education and environmental welfare components and also a method for determining weight coefficients for calculating an integral index that involves the use of a hierarchy analysis method. Because this method is a more reliable and consistent for assigning estimates to weight coefficients by experts, and is based on a pairwise comparison with each aspect of human development to determine relative importance.

Approbation of the results on the example of statistical data of regions of Ukraine allows obtaining a modified model of integrated assessment of human development. It will allow formulating the main recommendations for elimination of sharply expressed unevenness of the development of regions of Ukraine and contributing to raising the level.

\section{References}

1. L. Kochubei, Scientific Papers Kuras IPES of NAS of Ukraine, 3(89), 44-70 (2018)

2. Z. Yaremko, Economic Analysis, 15(1), 216-227 (2014)

3. Internet World Stats. URL: https://www.internetworldstats.com/stats.htm (2019)

4. T. Pospelova, ESP, 3, 366-376 (2017)

5. J. H. Nord, M. T. Riggio, J. Paliszkiewicz, JofCIS, 57(3), 278-285 (2017)

6. O. Saebo, R. Gomez, L. F. Baron, HICSS Jan 05-08, 2697-2697 (2016)

7. A. X. Herrera Marquez, F. Cervantes, P. Cervantes, EDULEARN, 8062-8072 (2015)

8. M. D. Lytras, E. Kurilovas, Computers in human behavior, 30, 361-361 (2014)

9. I. Bachylo, O. Sosnin, Yurydycheskyy visnyk Ukrayiny, 50 (2011)

10. UNDP, Human Development Report (New York: Oxford University Press, 1990)

11. UNDP, National Human Development Report. Local and Regional Development URL: http://hdr.undp.org/en/content/local-and-regionaldevelopment-poland-2012 (2012)

12. Lin. Yang, An Inventory of Composite Measures of Human Progress URL: http://hdr.undp.org/en/content/inventory-compositemeasures-human-progress (2014)

13. Z. Hermansons, Measuring Human Development at the Local Level: A Case Study of Latvia (Budapest, Hungary, 2015)

14. K. Mazumdar, Review of Social Economy, 61(4), 535-549 (2003)

15. M. A. Salas-Bourgoin Cepal Review, 112, 29-44 (2014)

16. M. Klekotko, A. Jastrzębiec-Witowska, K.Gorlach, P. Nowak, EEC, 24 (2018)

17. R. P. Yakunina, G. A.Bychkov, Procedia Economics and Finance, 24 (2015)

18. Technical notes: Human development indices and indicators. URL: http://hdr.undp.org/sites/default/files/hdr2018 technical notes.pdf (2018)

19. About general secondary education in Ukraine. URL: https://zakon.rada.gov.ua (2018)

20. O. V. Makarova, O. M. Hladun, Statistic of Ukraine, 1(56), 10-15 (2012)

21. UNDP, Human Development Report. The Real Wealth of Nations: Pathways to Human Development. (New York: Oxford University Press, 2010)

22. O. Vlasiuk, S. Pyrozhkov, Human Development Index: Ukraine's Experience (Kyiv: National Institute for Strategic Studies, 1995)

23. State Statistics Service of Ukraine. URL: http://www.ukrstat.gov.ua (2018) 